\title{
About "Learning" and "Analytics"
}

\author{
Arnon Hershkovitz, Simon Knight, Shane Dawson, \\ Jelena Jovanović, Dragan Gašević \\ Editors, Journal of Learning Analytics \\ jla.editorial@gmail.com
}

\begin{abstract}
This issue of the Journal of Learning Analytics features three special sections that look into topics of learning analytics for 21st century skills, multimodal learning analytics, and the sharing of datasets for learning analytics. The issue also features a paper that looks at models for early detection of students at risk in tertiary education. The editorial concludes with a summary of the changes in the editorial team of the journal.
\end{abstract}

Keywords: learning analytics, 21st century skills, multimodal learning analytics, data sharing

\section{INTRODUCTION}

In recent years, the field of learning analytics (LA) has made tremendous progress in expanding the scope of both the analytics it uses and the learning it measures. The methods employed to analyze educational data have continued to shift from a focus on gross predictive models to more advanced statistics and machine learning techniques associated with individual learner behavior. In this respect, it is becoming increasingly apparent that "analytics is at present in a space where research is rapidly outpacing current practice and broad scale sector understanding of how such information can be applied in education" (Dawson, Mirriahi, \& Gašević, 2015). Conversely, the types of learning that has been studied using learning analytics are just the tip of the iceberg compared to what is occurring in many educational settings. For example, it is common to use learning analytics for measuring scientific content-based knowledge, and even for measuring science inquiry skills (e.g., Gobert, Sao Pedro, Raziuddin, \& Baker, 2013). However, could this be further extended to consider measuring "ideas about science" (Osborne, Collins, Ratcliffe, Millar, \& Duschl, 2003)?

In recent years progress has been made towards measuring constructs that were previously considered as ill-defined, such as creativity (Dawson and Siemens, 2014; also this issue: Learning Analytics for 21st Century Competencies), collaborative learning (Koh et al., 2016), or self-regulated learning (Siadaty, Gašević, \& Hatala, 2016). Indeed, when referring to learning in todays' era (from schools to organizations to lifelong learners), content is no longer king. It is the more loosely y defined "new skills", aka 21st century skills have been given increasing prominence within the education discourse. For instance, the European Commission has recently adopted a new Skills Agenda for Europe, part of which is DigComp 2.0, a digital competence framework for citizens (Vuorikari, Punie, Carretero, \& Van den 
Brande, 2016); the framework includes competences in five dimensions, including information and data literacy (e.g., managing data, information and digital content); communication and collaboration (e.g., netiquette); digital content creation (e.g., integrating and re-elaborating digital content); safety (e.g., protecting the environment); and problem solving (e.g., creatively using digital technology). While the teaching of these skills in multi-disciplinary settings is a considerable challenge, the ability to measure the development and learning progression of these skills using learning analytics is even a greater one.

Many studies have successfully used learning analytics to identify students' affective and socio-affective states, as well as metacognitive behavior (e.g., Dowell \& Graesser, 2014; Pardos, Baker, San Pedro, Gowda, \& Gowda, 2014; Segedy, Kinnebrew, \& Biswas, 2015). These studies further illustrate that learning analytics is not solely confined to models of learning focused on content acquisition. When referring to "measures of learning, change and success", the Call for Papers for LAK Conferences explicitly mentions measures of non-content aspects of learning, such as affect, emotion, flow, conceptual change, expectations, metacognition, motivation, off-task behavior, satisfaction, and more. However, the "new skills" agenda as articulated by the European Commission may set a new bar for learning analytics. The lack of an authoritative definition associated with the various "new skills" as well as an understanding of how such skills are operationalized across educational settings may negatively impact LA progress in this area.

Thinking about the various ways to conceptualize and operationalize complex variables such as the "new skills" and, generally, metacognitive, affective and emotional variables necessitate a multidimensional method for measuring. This means that data is analyzed based on a few channels, often of different modalities and different granularities. For example, a learning experience using a computer-based learning system can be studied by analyzing videos of the screen (using a capturing software) and of the learner's face (using a webcam); data about the learner's eye-gazing (using an eye-tracking camera) and mouse movements (using a recording script); the learning system's logged data; and an audio of the learner while using the system (using a recorded think-aloud interview). These data can be further combined with data from sources such as biosensors (measuring, e.g., skin conductivity, heartbeat, or EEG), infrared imaging, and gesture sensing. Putting all these data together is a complex but it also has a great potential for shedding new light on the learning processes (cf. Blikstein, 2013). The capacity to analyze the "new skills" that form part of the broader global educational discourse alongside the development of new methods for analyzing multimodal data are two interwoven challenges that will drive the field forward.

\section{IN THIS ISSUE}

This issue presents three Special Sections. The first one is focused on using learning analytics to explore the "new skills"; it is titled Learning Analytics for 21st Century Competencies, and is guest-edited by Simon Buckingham Shum and Ruth Deakin Crick. The papers comprising this special section explore learning from a relatively high-level perspective. Specifically, Crick was the developer of CLARA (Crick 
Learning for Resilient Agency) self-assessment instrument, which measures seven dimensions of "learning powers", such as sense-making, curiosity, belonging, and hope and optimism. Buckingham Shum explores ways to analytically track learner qualities that have been hard to measure, as personal reflection, dispositions towards learning, etc.

In their introduction to this Special Section, Buckingham Shum and Crick define the 21st century competencies in light of the ever-growing literature in this field, discuss the analytics of these competencies, and ponder on the purposes of analytically measuring them. The papers published in the Special Section present the state-of-the-art in researching these new skills, regarding theory, methodology and impact. All in all, the five research and two practitioner papers discuss a rainbow of competencies, such as engagement, crowd-sourced learning, effort and persistence, and higher-order thinking.

The second Special Section, Multimodal Learning Analytics, discusses ways of analyzing data of different types and from different sources, and is edited by Xavier Ochoa and Marcelo Worsley. This Special Section is published after a few workshops on this topic have been conducted in recent years, most recently in LAK 2016 (Edinburgh, Scotland) and in ICLS 2016 (Singapore). The papers in the Special Section discuss such variables as attention, public speaking skills, and epistemological framing.

The third Special Section refers to another challenge that our community has faced: data sharing. This is a key for having a thorough discussion of various issues within our field. Researchers should make efforts to make more data available to the community, in order to facilitate replication studies and to further investigate previously-researched datasets. This Special Section, Dataset Description for Learning Analytics, is edited by Stefan Dietze, George Siemens, Davide Taibi, and Hendrik Drachsler; it collects and reports on four datasets, each of which is presented and explained (and, of course, linked). We hope that this is a first step towards making more data accessible to more researchers.

In addition, this issue includes another regular research paper by Geraldine Gray, Colm McGuinness, Philip Owende, and Markus Hofmann, titled Learning Factor Models of Students at Risk of Failing in the Early Stage of Tertiary Education. In this article, the authors demonstrate how data about first year students in tertiary education may yield critical information about their risk of failing.

We hope you will enjoy this rich and interesting issue.

\section{EDITORIAL TEAM UPDATE}

In our last editorial, we outlined the forth coming changes in the Journal's editorial team. Since the last issue, we have held an open call for editorial positions. We received a high number of outstanding applications. Among them, the committee appointed by the Society for Learning Analytics (SoLAR) selected the new editorial team and the SoLAR Executive Committee approved their appointments for three years. It is our privilege to announce new editors of the journal: 
- $\quad$ Arnon Hershkovitz is a senior lecturer in the School of Education at Tel Aviv University in Israel. He brings a wealth of experience in educational data mining and the learning sciences and will serve as a great link with the two sister communities.

- Xavier Ochoa is a professor in the Faculty of Electrical and Computer Engineering at the Escuela Superior Politécnica del Litoral in Ecuador. He is a long-serving member of the SoLAR Executive Committee, chair of LAK'13, and program chair of LAK'17, and has played a leading role in technology-enhanced learning in Latin America.

- $\quad$ Alyssa Wise is an associate professor in in the Steinhardt School of Culture, Education, and Human Development at New York University in USA. She is a long-serving member of the SoLAR Executive Committee, general chair of LAK'17 and brings a strong link between learning analytics and the learning sciences.

We are also fortunate to announce that Simon Knight, who is a research fellow in the Connected Intelligence Centre at the University of Technology Sydney in Australia, is appointed as the new editor of the practitioner Hot Spots section of the journal. He is a talented early career researcher who has played a prominent role in the learning analytics committees and actively contributed to the organization of previous LAK conferences.

We are very fortunate that our new editorial team represents a wide range of geographical regions and disciplines, which will play a critical role in the healthy development of the field of learning analytics. They have already started working on new initiatives in the journal clearly bringing fresh ideas and advancing the quality of the journal. You will have a chance to read about some of the on-going projects and innovations in the publication types and process in the editorials in future issues.

To allow for a smooth transition between editorial teams, some of the new editors will start their service in parallel with the existing editors. Arnon and Simon have already started their service as of July 2016, while Alyssa and Xavier will assume their roles in April 2017. Jelena will continue her service until December 2016 when Negin will return from her maternity leave. Negin will serve until April 2017 when she will retire form the editorial team together with Shane and Dragan.

\section{REFERENCES}

Blikstein, P. (2013). Multimodal learning analytics. Proceedings of the Third Conference on Learning Analytics and Knowledge (LAK'13), 102-106. http://dx.doi.org/10.1145/2460296.2460316

Dawson, S., \& Siemens, G. (2014). Analytics to literacies: The development of a learning analytics framework for multiliteracies assessment. The International Review of Research in Open and Distributed Learning, 15(4), 284-305. Retrieved from http://www.irrodl.org/index.php/irrodl/article/view/1878 
Dawson, S., Mirriahi, N., \& Gašević, D. (2015). Importance of theory in learning analytics in formal and workshop settings. Journal of Learning Analytics, 2(2), 1-4. http://dx.doi.org/10.18608/jla.2015.22.1

Dowell, N.M.M \& Graesser, A. (2014). Modeling learners' cognitive, affective, and social processes through language and discourse. Journal of Learning Analytics, 1(3), 183-186. Retrieved from https://epress.lib.uts.edu.au/journals/index.php/JLA/article/view/4203

Gašević, D., Dawson, S., \& Jovanović, J. (2016). Ethics and privacy as enablers of learning analytics. Journal of Learning Analytics, 3(1), 1-4. http://dx.doi.org/10.18608/jla.2016.31.1

Gobert, J., Sao Pedro, M., Raziuddin, J., \& Baker, R.S. (2013). From log files to assessment metrics: Measuring students' science inquiry skills using educational data mining. Journal of the Learning Sciences, 22(4), 521-563. http://dx.doi.org/10.1080/10508406.2013.837391

Koh, E., Shibani, A., Tan, J. P. L., \& Hong, H. (2016). A pedagogical framework for learning analytics in collaborative inquiry tasks: An example from a teamwork competency awareness program. Proceedings of the Sixth International Conference on Learning Analytics \& Knowledge (LAK'16), 74-83. http://dx.doi.org/10.1145/2883851.2883914

Osborne, J., Collins, S., Ratfcliffe, M., Millar, R., \& Duschl, R. (2003). What "ideas-about-science" should be taught in school science? A Delphi study of the expert community. Journal of Research in Science Teaching, 40(7), 692-720. http://dx.doi.org/10.1002/tea.10105

Pardos, Z., Baker, R.S.J.d., San Pedro, M., Gowda, S.M., \& Gowda, S.M. (2014). Affective states and state rests: Investigating how affect and engagement during the school year predict end-of-year learning outcomes. Journal of Learning Analytics, 1(1), 107-128. Retrieved from https://epress.lib.uts.edu.au/journals/index.php/JLA/article/view/3536

Segedy, J.R., Kinnebrew, J.S., \& Biswas, G. (2015). Using coherence analysis to characterize self-regulated learning behaviours in open-ended learning environments. Journal of Learning Analytics, 2(1), 13-48. Retrieved from https://epress.lib.uts.edu.au/journals/index.php/JLA/article/view/4129/4834

Siadaty, M., Gašević, D., \& Hatala, M. (2016). Trace-based micro-analytic measurement of self-regulated learning processes. Journal of Learning Analytics, 3(1), 183-214. http://dx.doi.org/10.18608/jla.2016.31.11

Vuorikari, R., Punie, Y., Carretero, S., \& Van den Brande, L. (2016). DigComp 2.0: The Digital Competence Framework for Citizens. Update Phase 1: The Conceptual Reference Model [Technical Research Report EUR 27948 EN]. Luxembourg Publications Office of the European Union. http://dx.doi.org/10.2791/11517 